\title{
RECEPCIÓN DE LA ARAUCANA EN ESPAÑA Y EUROPA: NACIONALISMO LITERARIO, CANON Y MIGRACIÓN
}

\author{
La Araucana's Reception in Spain and Europe: Literary Nationalism, Canon \\ and Migration
}

\section{RESUMEN}

El artículo se propone revisar el contexto de producción y de recepción de La Araucana, considerando los paratextos, ediciones e historiografía literaria, tanto en España como en Europa. Examina también el recorte nacionalista hispánico, la canonización y anclaje de la obra y su potencial migratorio en términos de pasar de un canon a otro, y, finalmente, la posibilidad de una doble pertenencia en términos de identidad nacional y literaria.

Palabras claves: recepción, historiografía literaria, épica, canon, migración.

\section{ABSTRACT}

the article aims to study the context of production and reception of the poem La Araucana. This, by considering editorial facts and literary historiography both in Spain and the rest of Europe. It also reviews the nationalistic approach, the literary canonization process, and the possibility of migration from one canon to another. Taking this into account, the articles argues for the double inscription of the poem in terms of national and literary identity.

Keywords: reception, literary historiography, epic, canon, migration.

\section{UNIVERSUM}

Revista de Humanidades y Ciencias Sociales

\section{BERNARDO \\ SUBERCASEAUX}

Profesor Titular Universidad de Chile, Chile.

Correo electrónico: besuberc@uchile.cl

ORCID: 0000-0003-1299

ResearchGate:

Scholar.google:

Academia.edu:

Agradezco el apoyo de Proyecto Fondecyt $\mathrm{N}^{\circ} 1170306$ "La Araucana: recepción y mutabilidad". Agradezco también la colaboración de Daniela Picón, Francisco Cuevas, co-investigadores y de Florencia Rabuco Quiroga, ayudante. 


\section{INTRODUCCIÓN}

Durante el Renacimiento español, con una importante presencia del pensamiento humanista - que se impone intelectualmente pero no en el plano institucional (Pérez, Joseph Humanismo) - se publica La Araucana (15691589), situada en el ámbito de un poder territorial institucionalizado en el Imperio de Felipe II, a la sazón triunfante y empeñado en ampliar sus fronteras. Se trata de espacios que albergan y preservan el patrimonio literario, instalando a la obra en una cadena filogenética y en un conjunto de cajas clasificatorias: el género épico, el Imperio, el Renacimiento, la poesía española italianizante y España como nación. La ambigüedad y mutabilidad del significado de la obra, que hemos analizado en detalle en otra oportunidad (Subercaseaux), obedece a que en ella coexisten distintas zonas de indeterminación semántica (crónica o poesía, historia o literatura, convenciones literarias o experiencia vital, españoles o indígenas, Europa o América, Marte o Venus, lógica imperial o lógica contestataria, etc.); en efecto, se trata de sentidos oscilantes que tensionan los parámetros tradicionales del género. La posterior movilidad del poema, que será reconocido como obra fundacional de la literatura chilena, pone en cuestión el recorte nacional —o más bien nacionalista - de la literatura, y también, porque no decirlo, de lo humano.

Nos proponemos estudiar la obra situándola en tanto en su paisaje editorial de origen, como en sus procesos de recepción en España y en Europa, examinando para ello los paratextos que la etiquetan, las reescrituras de cuño contrarreformista que deconstruyen sus personajes y una historiografía literaria que la canoniza, vale decir, la visibiliza culturalmente incluyéndola en el catálogo de obras selectas españolas que deben ser conocidas e imitadas. Desde esta posición, la obra irá levando anclas hacia otros territorios, proceso que tiene como trasfondo - tanto en España como en Inglaterra y Chile — situaciones nacionales e históricas políticas que van relevando ciertos horizontes de lectura en desmedro de otros. 


\section{EDICIONES, RECEPCIÓN Y BAUTIZO}

Las numerosas ediciones impresas durante el siglo XVI y XVII de $L a$ Araucana, tanto en España como en Europa (Bélgica, Holanda, Portugal), dan cuenta del enorme interés que provocó y de su temprana popularidad. José Toribio Medina anota, por lo menos, 17 ediciones y reediciones entre 1569 (Primera Parte) y 1600, año en que ya se habían editado la Segunda Parte (1578) y Tercera Parte, esta última en en1589 (Medina Ediciones). Más recientemente, Maxime Chevalier señala que entre 1569 y 1630 la obra tuvo 23 ediciones (106); fue leída, dice, por la fracción culta de hidalgos y caballeros, por letrados y catedráticos, por funcionarios, soldados y sectores del clero, e incluso por doctos que se interesaron por sus recursos retóricos. Ya en 1571, Lorenzo Palmireno la elogia en su manual de retórica, aun cuando recién se ha publicado la Primera Parte (Amor, 937). En Iberian Books: Books published in spanish or portugueses or in the Iberian Peninsula before 1601, un compendio reciente (2010) de libros publicados en España durante el siglo XVI, se consignan nueve ediciones de la Primera Parte entre 1569 y 1577, siete ediciones de la Primera y Segunda Parte más dos reediciones de la primera entre 1578 y 1589 y, finalmente, doce ediciones de la obra completa entre 1589 y 1597; vale decir, treinta ediciones de La Araucana desde 1569 hasta 1600 .

En Portugal fue conocida y admirada por el propio Camões. Las reediciones de la Primera Parte (1574 en Salamanca, 1575 en Amberes y 1577 en Zaragoza) estimularon la dedicación del autor a continuarla, dando lugar - finalmente - a una trilogía. Frank Pierce entrega abundante información sobre el aprecio que experimentó la obra y la figura de Ercilla en Europa, no solo entre sus contemporáneos sino también durante los siglos XVII, XVIII y XIX. "Hablar de Ercilla", señala, "es hablar de una figura inmortal de la literatura" ibérica, un autor que constituye "una presencia permanente en la conciencia poética española" (Pierce La poesía 271).

Para valorar el éxito de la obra de Ercilla, cabe tener en cuenta que la imprenta se estableció en Madrid en 1566, es decir, solo tres años antes de que 
se publicara la Primera Parte de La Araucana, y apenas ciento veinte después de su invención por Gutenberg. A propósito de la edición de Amberes, Bélgica (1575), Medina cita un testimonio de un correo militar que da cuenta de la recepción que tuvo la Primera Parte en 1570:

Estando yo en Bruselas, pueblo del ducado de Brabante, como un correo llevase allá un cuerpo de ella [La Araucana], fue recibido con tal aprobación y estimación entre los cortesanos y gente de milicia allí residentes, dados a la poesía, que unos le igualaban con Ariosto y otros le concedían mayor lugar que él (Medina Los Romances 525).

Según Medina, fue este entusiasmo el que llevó al editor Jean Bellere a emprender la tarea de traducir la obra y publicar una edición de bolsillo para que la llevasen los soldados y antiguos camaradas de Ercilla, y así poder "solazarse con ella en sus ratos de ocio en los campamentos" (ibid.). Este testimonio da cuenta de una lectura en que se conjugan lo histórico y lo estético, la aventura militar y el deleite literario. En efecto, en la época ya se afirmaba que el autor y su obra eran ejemplo de que las letras no embotan las armas, configurando así un nuevo ideal renacentista y un modelo de cortesano.

El interés literario por La Araucana estuvo acompañado desde su aparición por la curiosidad por una tierra ignota, zona que fue llamada "Nueva Extremadura" debido al origen extremeño de Pedro de Valdivia y varios conquistadores del territorio. Geográficamente, se la percibía como confín del mundo, lo que en época de Felipe II era equivalente a decir confín del Imperio. Fue concebida como fuente histórica de la Conquista desde el siglo XVI por los principales cronistas del Reino de Chile; Antonio de León Pinelo, por ejemplo, la consigna en su bibliografía de 1629 (De León Pinelo, Epitome) como un documento importante que funciona como relato y crónica durante más de tres siglos, puesto que las obras propiamente históricas sobre la Conquista solo empezaron a publicarse en el siglo XIX. Además, por referirse a sucesos contemporáneos, La Araucana fue objeto de una doble mirada: por una parte fue considerada por como un poema heroico e histórico que trataba temas recientes, lo que le significó reconocimiento literario entre algunos críticos. Desde otro punto de vista, sin embargo, fue objeto de críticas, 
pues estudiosos y preceptistas argumentaban que se trataba más bien de una crónica en verso que de un poema épico ajustado a la tradición. Entonces, esta discusión en que ya desde el siglo XVI se hacían presentes los dos principales enfoques con que la crítica y la historiografía han abordado la obra a lo largo del tiempo: el histórico y el estético.

Una revisión de los libros publicados por las distintas imprentas en Madrid desde su instalación en 1566 hasta 1600, nos puede dar una idea de lo que se editaba y leía en la época: de un total de 769 títulos impresos, 240 (casi un tercio) eran de temas religiosos, "tratados de mucha doctrina y provecho" (Pérez Pastor Bibliografía, 14); 220 de jurisprudencia (Derecho Canónico y Derecho Civil y Político); 134 de historia, 60 de poesía (la mayoría romances y poemas épicos religiosos, pero también 7 reimpresiones de la obra de Ercilla, considerando la Primera, Segunda y Tercera Parte); sumado a eso, algunas traducciones del Orlando el Furioso de Ariosto, de las Lusíadas de Camões, de la Jerusalén Libertada de Torcuato Tasso; se imprimieron también algunas obras de Lope de Vega y Jorge Manrique; finalmente, aparecen 20 obras que el autor y bibliógrafo Presbítero Cristóbal Pérez agrupa como "Fábulas, novelas, proverbios, emblemas y epistolarios", entre ellas el Guzmán de Alfarache de Mateo Alemán, la Diana de Jorge Montemayor y el Lazarillo de Tormes por Diego Hurtado de Mendoza. Cabe destacar que, en cuanto a los retratos que acompañan a los impresos, el primer lugar lo ocupa según el bibliógrafo Alonso de Ercilla, seguido por Lope de Vega.

En los paratextos editoriales de La Araucana durante los siglos XVI, XVII y XVIII, tanto españoles como europeos en general, abundan portadillas o prólogos con dos contenidos que se repiten: por una parte, se alude al vínculo imperial de la obra dedicada a Felipe II y, por otra, al carácter de hijodalgo, noble y cortesano de su autor. Además, usualmente se adjunta una imagen, ya sea un dibujo o un grabado de la cabeza y torso de Ercilla, coronado de laureles o escribiendo con pluma e indumentaria de soldado, con armas en el trasfondo. De este modo, se lo resalta como figura heroica, como soldado conquistador y también como príncipe de los poetas, lo que trasunta una porosidad entre dos géneros: la crónica y la épica. Varias reimpresiones vienen precedidas por una 
dedicación "Al católico monarca don Felipe V, Rey de las Españas y emperador de las Indias", casi todas las ediciones anteriores al siglo XIX incorporan datos de la vida de Ercilla, y en muchas portadas figura al pie de la imagen: "Don Alonso de Ercilla y Zúñiga, gentilhombre de Cámara de la Majestad del Emperador Dirigidas al Rey Nuestro Señor", o bien "Excelentísimo caballero e ilustre poeta", o "Príncipe de las poesías heroicas de España". Incluso, en ediciones impresas en el extranjero se lo califica de "Príncipe de la poesía de su patria”. Así, desde la edición de la Primera Parte (1569) en adelante, ambos tópicos (el marco imperial y su biografía) se complementan.

Ahora, lo primero que se consigna en los prólogos o introducciones es la pertenencia de Ercilla a la nobleza: "Gentil Hombre de su Majestad, y de la boca de los Serenísimos Príncipes de Hungría. Dirigida a la S.C.R.M. del Rey don Phelippe nuestro Señor". Luego, con la finalidad de confirmar este vínculo, se alude a "los servicios al monarca desde pequeño como paje", o bien al rol que desempeñaron en la corte su padre, destacado jurista y asesor de Carlos V, y su madre, Dama de la Corte. Varios editores, además, hacen referencias elogiosas de su persona: "valentísimo soldado, diligente historiador y famosísimo poeta". Entre las notas biográficas, la que más se repite es su pertenencia a la Orden de Santiago, a la que ingresó por Cédula Real en 1571. En aquel entonces, ser caballero de la Orden de Santiago significaba pertenecer a una Orden religiosa y militar —que debía su nombre al Santo Patrón de España - fundada en el siglo XIII e incorporada en 1495 a la Corona. Para ser miembro, primero había que ser hidalgo en los cuatro primeros apellidos (de sangre afuero de España y no de privilegio), luego probarse que ni los padres, ni los abuelos habían ejercido oficios manuales, y que no tenía antecedentes de judío, pagano o musulmán. En consecuencia, que el autor fuera parte de esta Orden probaba su estatus de cristiano viejo en una España inquisitorial que enaltecía los signos de pureza. Los paratextos, sobre todo de las ediciones de los siglos XVI hasta el XVIII, también apuntan a españolizar el poema, inscribiéndolo en los valores predominantes del Imperio, en la institucionalidad de la Corona, en la territorialidad del poder, en la corte y en la proximidad al soberano; en fin, en una sociedad de castas 
en que la nobleza y los altos funcionarios del Estado y la Iglesia eran los sectores dominantes. De este modo, parte importante de la recepción de $L a$ Araucana estuvo mediada por la presentación de su autor como una figura que encarna el ideal renacentista de las armas y las letras, en una sociedad estratificada. Tales son las señas que bautizan editorialmente al poema en el Viejo Mundo, que lo etiquetan y encasillan, promoviendo horizontes de lectura muy ajenos a los temas que van a ser abordados en el siglo XVIII por los preceptistas, preocupados más bien de si se trataba de un poema épico en la tradición aristotélica del género, o de una crónica rimada de hechos históricos. Lo que quedaba fuera de discusión crítica, por el momento, era su pertenencia al canon de la poesía española.

Por otro lado, hubo también recepciones negativas de la obra, tanto en España como en Europa; en España, por ejemplo, las hubo por personajes próximos a García Hurtado de Mendoza, como Cristóbal Suarez de Figueroa, quien publica — por encargo- Los hechos de Don García (1613). En esta obra describe a La Araucana como un poema acéfalo que omite el rol de don García en Arauco, calificando a Ercilla como "un soldado ingrato" (23). Más tarde, fundamentalmente durante el siglo XVIII, se criticará desde una óptica neoclásica el desajuste de La Araucana respecto a las normas de la épica establecidas por Aristóteles y ejemplificadas en la épica antigua y clásica. Se criticará, así mismo, la carencia de unidad poética (por estar compuesto por tres partes distanciadas en el tiempo), la ausencia de héroe y el carácter inconcluso del poema. Es más, se llegará a negar su condición de tal, categorizándolo solo como una crónica de valor histórico.

Una recepción crítica de considerable influencia fue la de Voltaire, quien en 1733 publicó su Essai sur la poésie épique, en donde inicialmente valora de forma positiva algunas descripciones, rescatando la arenga de Colo-Colo, a la que considera superior al discurso de Néstor en la Ilíada. Sin embargo, en el resto de la obra, Voltaire advierte falta de invención, monotonía y carencia de unidad, concluyendo que el poema es más salvaje y primitivo que la nación de Arauco a la que tiene por tema. Simonde de Sismondi, historiador literario suizo, plantea en 1813 un juicio negativo de toda la épica española, y en 
particular de La Araucana: "nadie la lee actualmente" (185) dice, y argumenta que solo gracias a la crítica de Voltaire se la rescató del olvido, afirmación que, como veremos, es discutible. Para ello, basta tener presente el interés que despertó la figura y obra de Ercilla en los románticos ingleses, entre otros, en William Blake.

En cuanto a contenido, el principal problema del itinerario editorial de La Araucana fue la existencia en vida de Ercilla de una edición con solo 35 cantos (la Primera Parte de 15, la Segunda Parte de 14 y la Tercera Parte solo de 6), lo que llevó a pensar que las 115 estrofas y los cantos 36 y 37 de la edición definitiva, posterior a su muerte, habían sido agregados por la viuda y el impresor de la obra, sin contar con la autorización del autor. Sin embargo, un estudioso y joven tesista - Juan Alberto Méndez Herrera - descubrió dos ejemplares de 1590 que incluían las 115 estrofas y los cantos 36 y 37, en una edición conocida y autorizada por Ercilla (Martínez). Se sabe que Ercilla corregía incluso cuando su obra estaba en proceso de impresión. El hallazgo evidencia que los dos últimos cantos y el viaje a Ancud no fueron agregados póstumamente, como suponían algunos investigadores. Se contradice así la hipótesis de que Ercilla se habría autocensurado negándose a publicar esas 115 estrofas. El asunto reviste importancia pues en la expedición a Ancud, como hablante y protagonista, Ercilla hace una abierta y explícita crítica a la empresa de la Conquista. Algunas ediciones posteriores a la muerte del autor no contienen ese episodio, y constan solo de 35 cantos. Resulta significativo pero comprensible que Ercilla no haya dejado testimonio sobre este tema, asunto complejo dado que - como hemos planteado anteriormente- su poema fue bautizado con el beneplácito del imperio. Silencio comprensible si se tiene en cuenta que en 1585 el propio Ercilla, ejerciendo como veedor y responsable de darle el "imprímase" a una traducción de Orlando el Furioso, de Ludovico Ariosto, escribió en el prólogo: "En esta traducción van quitadas las cosas licenciosas, y las impertinentes para nuestra nación. $\mathrm{Y}$ en todo lo demás va fiel y en buen romance" (Ercilla en Pérez Pastor, 114). 


\section{REESCRITURAS}

La resonancia que tuvo La Araucana en el siglo XVI y primeras décadas del XVII también se hace patente en España a través de las reescrituras literarias e históricas (Massman) de temas, tópicos, acontecimientos y personajes. De acuerdo con Medina, varios romances incluidos en el Ramillete de Flores (1593) basan su argumento en episodios o motivos provenientes de la obra (Los Romances). Son años en que el romance era el género más leído y popular. Apropiarse de tópicos y episodios aislados - el desafío entre Tucapel y Rengo - implicaba popularizar en romance a personajes y episodios, desligándolos de la totalidad de la trama, para instalarlos en el ámbito de la poesía popular española. El autosacramental La Araucana, presentado a fines del siglo XVI, atribuido inicialmente a Lope de Vega, pero luego a Andrés de Claramonte (Autosacramental La Araucana. Estudio Rodrigo Faúndez), constituye un ejemplo del sentido en que se proyectan algunas de estas reescrituras. La pieza en un acto es una versión en clave alegórica y cristológica basada en la prueba del tronco y la elección de Caupolicán, personaje que es concebido como Cristo y el madero como la cruz. El héroe es deconstruido como tal y representado como un dechado de virtudes cristianas de abnegación y sacrificio. Colo-Colo, a su vez, será configurado como San Juan Bautista. El autosacramental concluye con una suerte de eucaristía en perspectiva de redención. La crítica ha percibido a Caupolicán como un Jesucristo indiano e híbrido, en la medida en que se lo saca de un espacio cultural y político y se lo traslada y mezcla con otro. Esta forma teatral de corte religioso y de énfasis eucarístico (luego de un interludio musical se produce la transubstanciación del cazabe y el maíz en el cuerpo de Cristo) se representaba en la fiesta de Corpus Christi y muy probablemente fue puesto al servicio de la evangelización (Rodrigo Faúndez en Estudio, Autosacramental La Araucana). Como es evidente, la transformación de personajes araucanos en figuras religiosas anula la pasión libertaria y la heroicidad que los identifica en la obra de Ercilla. Se trata de una reescritura que obedece a un trasfondo contrarreformista, en el que el mundo araucano es reemplazado por una 
cosmovisión católica, por un espacio cristológico y de resonancias bíblicas y, por ende, despojado de su carácter de resistencia a la Conquista.

Otro autor contemporáneo que aborda la obra y personalidad de Ercilla es Lope de Vega (1562-1635), quien en Laurel de Apolo (1630), poema que reúne a los grandes ingenios de las letras españolas convocados al Parnaso, incluye en esta nómina a Ercilla:

Don Alonso de Ercilla / tan ricas Indias en su ingenio tiene, / que desde Chile viene/ a enriquecer las Musas de Castilla; / pues del opuesto polo/trujo el oro en la frente como Apolo, / porque después del grave Garcilaso, / fue Colón de las indias del Parnaso (Lope de Vega 87)

Lope alaba a Ercilla como poeta ultramarino que trajo lo que estaba en América a las Musas de Castilla, desde el allá hacia el acá, operación que como veremos - diluye la polaridad y ambigüedad semántica de La Araucana. En esta misma línea, publica en 1625 la tragicomedia Arauco Domado por el excelentísimo señor Don García Hurtado de Mendoza, pieza que tiene como referencia al Arauco Domado de Pedro de Oña (reimpreso en España en 1613) y a La Araucana. Se trata de un texto laudatorio que configura como héroe a Don García. Tal como Suárez de Figueroa, se propone reparar una omisión de Ercilla, probablemente también por encargo de los Hurtado de Mendoza. De hecho, la figura de Ercilla es directa e indirectamente denostada: la pieza va precedida por una dedicatoria del autor al Marqués de Cañete, en la que se propone relatar la "verdadera historia" de los vencimientos y hazañas de quien fue "freno español y yugo católico de la más indómita nación que ha producido la tierra en la parte cuyo descubrimiento dio tanta gloria a España" (Martínez Chacón 237). Aun cuando en boca de los personajes araucanos el autor utiliza algunos vocablos supuestamente indígenas, se trata, como ha señalado Elena Martínez Chacón, de "araucanos españolizados" (244). También hay bailes y canciones pretendidamente americanas, y alguna presencia de lo gracioso propio de las comedias de Lope. El eje del argumento es, sin embargo, el rol desempeñado por Don García, al que se perfila como un héroe capaz de someter a los araucanos, gracias a quien son derrotados y Chile se rinde ante el Imperio. Como el autosacramental, la tragicomedia tiene también un trasfondo 
contrarreformista, de hecho, en la dedicatoria al Marqués de Cañete Lope de Vega se identifica significativamente como "Su Capellán". Allí, mientras que Caupolicán es presentado como un idólatra y rebelde, Don García representa al Imperio como brazo del catolicismo. En este contrapunto, la empresa española no es una mera expedición de Conquista sino una mezcla de aventura y servicio divino, en que se articulan aspectos básicos "del respirar español de entonces: el Imperio, la religión y el heroísmo" (Martínez Chacón 236).

Algunos personajes de la obra de Ercilla han sido incorporados en el teatro del Siglo de Oro. Uno de ellos es Tucapel, personaje que en La Araucana, más allá de la prudencia, representa la fuerza y valentía sin límites, particularmente en su disputa con Rengo. Ariel Núñez ha demostrado cómo en distintas piezas teatrales Tucapel va siendo configurado como guerrero intrépido, luego como galán o amante y, finalmente, como gracioso calderoniano, típico de la comedia de enredos. Este proceso acaba por diluir los rasgos épicos del personaje, para terminar insertándolo en otro código. Es una transformación que lo anula como sujeto indómito, reduciéndolo a las convenciones de la comedia de enredo del teatro barroco, ajeno ya al contexto de Arauco. Del modelo ercillano del personaje lo único que se conserva es su rivalidad con Rengo, sin embargo, la contienda "con el español es solo un duelo individual que no reviste ninguna connotación” libertaria (Núñez 140).

La reescritura más directa de la Araucana fue un intento de continuarla, se trata de la Cuarta y Quinta Parte, en que se prosigue y acaba la historia de D. Alonso de Ercilla hasta la reducción del Valle de Arauco, en el reino de Chile (1597), obra de Don Diego de Santiesteban Osorio, natural de la ciudad de León, publicada en Salamanca y reeditada por Francisco Martínez Abad en 1733 y 1735. En la época, fue también encuadernada en conjunto con las tres partes originales de la obra de Ercilla. La cuarta parte consta de 13 cantos y la quinta de 20, y culmina con la derrota definitiva de los araucanos, consignada en la estrofa final para honra del Imperio: 
Rendidos a su estrella y duros hados / quedaron hoy los indios, y murieron/al rigor de españoles entregados, / que a todos una misma muerte dieron: / quedaron aunque muertos, coronados / pues con tanto valor se defendieron / vencidas las indómitas naciones, /Antárticas, y bárbaras regiones.

La continuación de Santiesteban —que no conoció personalmente las Indias ni participó en la Conquista - es pobre y forzada en su versificación, pero temáticamente concluye lo que en la obra de Ercilla había quedado inconcluso: la derrota del bando araucano. Tras todas estas reescrituras y paratextos hay un proyecto que busca diluir las ambigüedades semánticas del original, anulando el encuentro de espacios, discursos y tiempos históricos diferentes. Son reescrituras que omiten las zonas de indeterminación y sentidos oscilantes de La Araucana para reinscribir elementos, personajes o motivos en códigos afines al anclaje español, a una nación de aires imperiales y contrarreformista. En consecuencia, el resultado es un posicionamiento acrítico de la obra en el cajón español y en el orden imperial de las guerras coloniales.

\section{DISPUTAS IMPERIALES}

Una situación distinta, pero que por lo mismo pone en evidencia el proceso que hemos descrito, es lo que sucede con las lecturas, traducciones y reescrituras de La Araucana en el ámbito anglosajón. Lecturas e intertextualidades que se dieron en el contexto de disputas imperiales que desde el siglo XVI enfrentaron a Inglaterra con España y Portugal. El tema ha sido estudiado por Frank Pierce en la década de los 60, quién señaló el interés de los románticos por la figura del buen salvaje y por el espíritu libertario de los araucanos. Más recientemente Bárbara Fuchs, hablando de La Araucana, examina la recepción que tuvo en los países bajos y en Irlanda, donde fue leída como crítica al Imperio Español (Fuchs). Posteriormente Rebecca Cole analiza lecturas británicas que ensalzaron a figuras araucanas refiriéndose tanto a la época de la Conquista como de la Independencia (Cole) y finalmente Daniela Picón, quien ha investigado en detalle la recepción de La Araucana en 
el mundo anglosajón en el contexto de las disputas imperiales y en cuyo texto $\mathrm{y}$ en los intercambios que tuvimos al respecto nos basamos en lo que sigue. ${ }^{1}$

En el ámbito británico, George Carew (1555-1629) tradujo parte de la obra de Ercilla (16 cantos) al inglés y en prosa. Carew fue, como señala Picón, una figura destacada en la administración colonial inglesa. Siguiendo a Bárbara Fuchs, dice que como administrador colonial Carew estuvo vinculado con la política antiespañola de la época, interesado particularmente en la experiencia de conquista de España, a la que condenaba por su codicia y crueldades (Fuchs). En este sentido, Carew encontró en La Araucana un texto plurisignificativo que, si bien contemplaba una lógica imperial, la desbordaba en el plano bélico, al manifestar "una especial simpatía por los indígenas enemigos de los españoles" (Picón, inédito). Las ambigüedades y contradicciones presentes en el poema, "así como la ausencia en éste de una resolución final del conflicto, habrían levantado sospechas en el estadista inglés" (Picón, inédito), quién habría decidido prescindir en su traducción de las dos últimas partes, por evidenciarse en estas un fracaso del intento de imaginar el "imperio de manera convincente" (Picón, inédito). Esta primera traducción en prosa de la obra en el contexto de disputas imperiales tiene como consecuencia que, en la recepción del poema a fines del siglo XVIII y comienzos del XIX, los románticos ingleses se interesaran no solo por el género épico, sino también se hiciesen cargo de las zonas de indeterminación del poema, a diferencia de la recepción hispánica que más bien las ignoró.

Las disputas imperiales fueron estimuladas también por la controversia religiosa entre protestantismo y catolicismo; famosas son las ilustraciones de Theodor deBry (1528-1598), ilustradory editor protestante que vivió en Londres entre 1585 y 1588, cuyos grabados en una edición de la Brevísima destrucción de las Indias de Bartolomé de las Casas, configuran un repertorio de crueldades y torturas que contribuyó a la leyenda negra de España. Más tarde, a fines del

1 Daniela Picón en "Recepción de La Araucana en el radicalismo inglés: William Hayley y Robert Southey”, artículo inédito pendiente de publicación. La autora de este artículo fue coinvestigadora durante dos años del proyecto Fondecyt, del que fue Investigador Responsable Bernardo Subercaseaux. 
siglo XVIII, los enciclopedistas franceses - cuyas ideas tuvieron repercusión en toda Europa - fueron también críticos de la Conquista y del Imperio español.

Afines del siglo XVIII, cuando se han relajado las exigencias neoclásicas a la poesía épica influenciadas por la crítica de Voltaire, el gramático y pastor evangélico escoces Hugo Blair sostiene, en Lectures on Rhetoric and Belles Lettres (1783), una postura ecléctica respecto a si un poema épico cumple o no con los parámetros aristotélicos, habla de "discusiones empalagosas ... fundadas en una sumisión servil a la tradición" (Blair, 138). ${ }^{2}$ En este contexto, William Hayley hace una segunda traducción de La Araucana, y publica su Essay on Epic Poetry (1783). El ensayo, resumen de algunos cantos y traducción de 1000 versos, despertó gran interés entre los románticos ingleses, entre otros, en William Blake, quien equiparó a Ercilla con Milton, Camões y Ariosto. Lo percibían como un héroe romántico: conquistador de día y poeta de noche. Los críticos y lectores ingleses se interesaron por la figura de Ercilla como ideal renacentista de las armas y las letras, pero también por su alabanza a los araucanos, a quienes valoraban por su espíritu indomable y su resistencia a la conquista. El estudio de Picón resalta el interés de Hayley por los acontecimientos en que desempeñan un rol destacado las figuras de Lautaro y Caupolicán, por el escenario y las costumbres de Arauco. Percibe a los araucanos como "salvajes de mente noble". Destaca, también, la crítica que realiza Ercilla como narrador y protagonista a la Conquista y a sus compatriotas.

Rebecca Cole y Daniela Picón mencionan a varios poetas ingleses que, a fines del siglo XVIII y comienzos del XIX, se interesaron por la visión positiva de Ercilla de los líderes araucanos. Entre ellos el poeta y ensayista Robert Southey (1744-1843), vinculado a los círculos románticos de avanzada. Southey, estudioso de La Araucana, publicó Madoc (1805), poema en que se propuso poetizar una "sociedad utópica e igualitaria emplazada en América" (Southey en Picón, inédito). Contrapone el mundo europeo, corrupto y

2 El texto de Blair, traducido por José Luis Munarriz, fue destacado por Camilo Henríquez en La Aurora (25 junio 1812) y tuvo uso docente en el Instituto Nacional. http://www. auroradechile.cl/newtenberg/681/propertyvalue-2366.html 
decadente, con el Nuevo Mundo, ejemplificándolo en una sociedad igualitaria de base indígena. La Araucana, que mostraba una marcada simpatía por los indígenas y sus valores, fue uno de sus referentes. En Madoc, Picón identifica algunos episodios y situaciones de inspiración ercillana. Percibe en el transcurso del poema una crítica al imperialismo, pero paralelamente advierte que el autor va legitimando la acción imperial británica como distinta a la española, como una conquista pacífica y benevolente, que contrasta con las crueldades cometidas por la otra. Como señala Picón, La Araucana fue leída como una obra que daba pie a un mal colonialismo frente a un buen colonialismo. El poema de Ercilla, concluye la autora, "se convirtió en una fuente desde la cual los escritores ingleses construyeron un mito que buscaba diferenciar a los buenos colonizadores británicos de los conquistadores ibéricos, con el propósito de estereotipar a españoles y portugueses como imperialistas crueles y brutales”. Picón también menciona a William Leslie Bowles, que publicó en 1813 The Missionary, poema extenso en que se levanta como figura a Lautaro en su relación con Pedro de Valdivia, con un trasfondo que marca una ruptura definitiva entre España y sus colonias. Desde esta perspectiva, los líderes araucanos fueron percibidos como figuras heroicas debido a su lucha por la libertad, valor el más caro para la sensibilidad romántica.

Como se aprecia, la jerarquía que le otorgan y lo que destacan de $L a$ Araucana en el mundo anglosajón indica un contexto de lectura y recepción distinto al hispánico, en que se conjugan el carácter polisémico de la obra y las disputas imperiales. Estos son los principales factores que han posibilitado lecturas distintas entre los siglos XVII y comienzos del XIX.

\section{HISTORIOGRAFÍA LITERARIA}

Durante los siglos XVII, XVIII y comienzos del XIX, previo al incremento de la historiografía literaria clásica de corte nacionalista y con fines pedagógicos, encontramos diversos géneros híbridos que seleccionan fragmentos o se refieren a La Araucana, o textos de preceptiva cuyos títulos revelan juicios canonizantes: "Principios filosóficos de la Literatura", "Arte 
Poética", "Biblioteca selecta de literatura española", "Ramillete de poesía", "Parnaso Español”, "Apéndice sobre la poesía épica española", "Ensayo histórico apologético de la literatura española", "Lecciones españolas de Literatura y de moral", "Cuadro de la literatura española", "Tesoros de los poemas épicos españoles, sagrados y burlescos", "Manual de Literatura Española", "Poesías selectas castellanas". En algunas se llama a Ercilla "nuestro Homero Español" y otras son obras - en algunos casos traducidas del francés - con un propósito pedagógico y de ordenamiento cronológico, pero que no son propiamente historias literarias en el sentido más convencional del género. Varias de ellas, en los siglos XVIII y XIX, lastradas por la poética y la retórica neoclásica y por la opinión de Voltaire, critican la obra de Ercilla como poema acéfalo, de estilo desigual y sin dignidad épica. Por otro lado, antologan versos, fragmentos y episodios, resaltando su valor estético. Así ocurre en Biblioteca selecta de Literatura española de Pablo Mendibil y Manuel Silvela (Burdeos, 1819), o en Lecons espagnole de Litterature et de morale de Victor Rendú (París, 1840). Otros autores, como Francisco Javier Lampillas, erudito y jesuita español, instalado en Italia luego de la expulsión de la Orden, discute en su Ensayo histórico apologético de la Literatura Española (1778-1781) las tres unidades aristotélicas y valora el anclaje de la obra de Ercilla con hechos contemporáneos y llama al poeta "Nuestro Virgilio Español". Todas contribuyen, sin embargo, a instalar a La Araucana en el canon español.

Un caso especial es la traducción que hace el crítico literario y ex rector de la Universidad de Salamanca, José Luis Munárriz, de Lectures on rethoric and Belles Lettres (1783) de Hugh Blair. Munárriz agrega de su propia cosecha un "Apéndice sobre la Poesía Épica Española" en que trata detenidamente a La Araucana. Señala que un buen poema épico es "la obra más difícil a que pueda aspirar el ingenio humano" (50). Amparado en el armazón teórico ecléctico de Blair, afirma que el poema de Ercilla pertenece cabalmente al género épico sin importar que sea histórico. Se refiere también, con algo de sorna, a los teóricos serviles a la tradición. Señala, empero, algunos defectos: plan incompleto, carencia de un héroe sobresaliente, episodios mal enlazados con la acción principal, estrofas que por momentos son "para cansar y 
aburrir al más flemático" (54-56). Debido a que se contradice, todo indica que la razón de su crítica proviene de una alabanza excesiva al valor de los araucanos, incluso con grave mengua del honor nacional: "A fuerza de querer" ensalzar a los araucanos Ercilla "ha oscurecido de tal suerte a los españoles, que solo aparecen como una sombra empleada para que resalten las figuras de sus enemigos: estos están retratados de mano maestra, los vencedores apenas bosquejados" (52). Desde este punto de vista y desde un enfoque histórico, Munárriz se queja de que el poema no resulta interesante ni lisonjero para "su propia nación" (52). Paralelamente a este reclamo nacionalista, en la parte más extensa de su texto relativiza "los defectos que en su invención y plan presenta el poema" (56). En efecto, cita y alaba con entusiasmo largos fragmentos de la obra particularmente referidos a Caupolicán, Lautaro y Galvarino y a sus arengas, así como descripciones y símiles llevados a cabo con un "pincel finísimo", señala incluso que Ercilla en algunos aspectos supera a Homero. Discute también la opinión negativa de Voltaire e insinúa que el autor probablemente no leyó la obra. De todo ello se colige que sus opiniones negativas se deben fundamentalmente a la crítica de la Conquista y al bando español. Munárriz entra — tal vez por primera vez — a cuestionar la ideología que subyace al poema. Se trata, en síntesis, de una crítica que valora estéticamente a La Araucana, pero que advierte en su motivación testimonial e histórica una deslealtad hacia España, juicio que abre la posibilidad de lealtad hacia otra nación.

Francisco Martínez de la Rosa, letrado y político de espíritu liberal, que participó en las Cortes de Cádiz (1812) y en la resistencia contra la invasión bonapartista, en su "Apéndice sobre la poesía épica española" (1827-1830), critica a La Araucana en términos de su plan y unidad de acción. A pesar de la consideración general negativa, resalta ciertas pinturas y señala aciertos expresivos en varios episodios, pero igualmente se suma a la tradición dieciochesca reiterando los defectos que la poética neoclásica había puesto sobre la mesa. Su crítica fundamental, de trasfondo nacionalista, coincide con las ideas de Munárriz: 
[...] en todo el poema no aparecen sino dos cualidades loables de los españoles, el valor en los combates y la constancia en los trabajos, pero deslustradas ambas prendas, tan propias del carácter de la nación, con la avaricia y la crueldad, pintadas por el poeta con el color más negro... Por el contrario, todo lo noble, todo lo heroico y extraordinario está de parte de los Araucanos. (50)

Diez años más tarde, en Tesoros de los poemas épicos españoles (1840), Martínez de Rosa sitúa a La Araucana como parte del blasón principal de la literatura española: "Suelen los pueblos cultos — dice — cuando logran tener en su lengua un poema heroico bien hecho, considerarle como el blasón principal de su literatura" (118); defiende también a la obra de Ercilla de las críticas de los preceptistas neoclásicos del XVIII. Sin embargo, en una edición de sus Obras Completas (1897-1898), siguiendo a Munárriz, señala que Ercilla falla en lisonjear a su propia nación. La ojeriza hacia Ercilla se mantuvo hasta el siglo XX: en Alrededor del Mundo (27 julio, 1910) un autor anónimo publica un artículo titulado "El poeta más arrogante de la España: un guerrero cantor condenado a la horca".

Manuel José Quintana, liberal contemporáneo de Martínez de la Rosa, en cambio, destaca y valora positivamente a La Araucana (Martínez de la Rosa Poesías Selectas en Obras Literarias): su lenguaje y capacidad narrativa, la caracterización de personajes (especialmente los héroes araucanos), la descripción de las batallas y de la tempestad y, sobre todo, la configuración del propio autor como personaje y voz que sostiene al poema. También, siguiendo a Boileau, advierte faltas métricas y de estilo.

El Manual de Literatura Española (1844) de Antonio Gil de Zárate incluye una primera parte sobre cuestiones de retórica y principios generales de literatura, y una segunda en que consiste en un resumen histórico de la literatura española. Establece así un deslinde entre retórica y poética e historia literaria. Con respecto a La Araucana, destaca la pintura de los araucanos en línea con el carácter humano y compasivo de su autor, la descripción de las batallas y las arengas de sus personajes. Selecciona episodios y discursos de Colo-Colo y Lautaro. Vincula la obra con la de Lucano y Camões sin 
considerar como referentes a Homero o a Virgilio. Su juicio, que combina aspectos críticos sobre el estilo y otros favorables, es más elogioso que los de sus predecesores. Gil de Zárate fue importante para la instalación de $L a$ Araucana en el canon, pues tuvo participación en la legislación educacional de la época y su Manual, en tres tomos, se convirtió en libro de texto obligatorio en los institutos de educación del país.

Manuel de la Revilla, en Principios Generales de la Literatura Española (1877), con una postura eminentemente estética y apegada a la tradición, señala que en los siglos áureos el género épico se encuentra en condición de inferioridad respecto de otros géneros. De todos los poemas épicos que existieron - dice- "no hay ninguno que merezca el nombre de tal", lo que explica porque "nuestros épicos" quisieron ser al mismo tiempo "poetas e historiadores verídicos" (121). Varios de los textos que tienen planteamientos similares a los de Revilla se guían por el Compendio de Arte Poética (1844) de Manuel Milá y Fontanals, obra de gran prestigio que sigue los principios de la retórica clásica. Milá fue profesor de estética y de historia de la literatura, su discípulo predilecto fue Marcelino Menéndez Pelayo, quien criticó ácidamente los planteamientos de Revilla. A pesar de que Milá fue impulsor de la estética romántica, en términos de la épica su postura fue rígida y conservadora. Define al género como "una relación poética de una empresa esclarecida, que generalmente tiene un interés peculiar para la nación en que se escribió" (95). Señala que no hay en España poemas épicos que puedan compararse con los antiguos, o con la épica italiana e inglesa. Sostiene que la manía "de poetizar la realidad histórica e inmediata" (104) ha sido el gran error de "nuestros épicos" (ibid.). Finalmente menciona a la obra de Ercilla de la que dice que contiene "muchos elementos poéticos" (ibid.).

En síntesis, los géneros híbridos que hemos revisado son en su mayoría selecciones, antologías o preceptivas que incluyen, nombran y etiquetan a $L a$ Araucana como un poema español sin más, instalándola en el canon, aun cuando la critican. Alaban algunos aspectos parciales, pero también señalan imperfecciones en relación a las exigencias de una estética neoclásica. Paralelamente, sin embargo, antologan y destacan con notas laudatorias 
fragmentos de la obra. Salvo en contadas excepciones, se desvaloriza su dimensión de crónica de hechos históricos contemporáneos. Algunos se quejan de que no realce ni prestigie a la nación, reclamo nacionalista que da por supuesto su territorialización y su pertenencia canónica a la España imperial. En todos ellos, casi sin excepción, opera el vaivén y la controversia entre un enfoque histórico y un enfoque estético.

\section{DEL CANON AL DOBLE CANON}

En cuanto género, las historias literarias tienen su auge en España y Europa en los siglos XIX y XX. Son textos o manuales descriptivos que ordenan la producción literaria con propósitos pedagógicos y nacionalistas. En este proceso se construyen genealogías, territorializan, canonizan o recanonizan obras, se hacen visibles y se les otorga un lugar jerárquico que se reproduce en la docencia. En línea con un modelo romántico positivista, aportan a la construcción cultural de la nación. Desde ese punto de vista, reducen la realidad literaria a cierta selección legitimada. Por lo general — sobre todo hasta la década de 1970 — se trata de una historiografía apegada a la tradición en términos de ordenamiento temporal y por géneros restringidos al área de la cultura culta y letrada. Corresponde, por ende, a una historiografía corporativa y seccionada (historia de la pintura, de la música, del teatro, etc.), a tono con la hegemonía cultural. Desconoce, por lo tanto, la heterogeneidad del campo literario, los paralelismos y sensibilidades que se confrontan o confluyen.

Descartando las historias literarias de gran envergadura y espectro geográfico europeo o universales que fueron publicadas inicialmente en francés, italiano o alemán y luego traducidas al español o consideradas como "Historia de la literatura española", lo que en efecto no eran (me refiero, entre otras, a la de Sismondi: De la litetterature du midi de l' Europe; a la de Juan Andrés y Morell, Origen y progreso del estado actual de la literatura (17821799), publicada originalmente en italiano, y a la de Friedrich Bouterwek Historia de la Literatura Española (1784-1806), a diferencia de ellas la obra historiográfica más importante apegada al modelo nacional es la de George 
Ticknor: History of spanish literature. Esta fue publicada simultáneamente en Londres y Nueva York en 1849, y traducida y editada en Madrid en 1851. Se trata de un manual ordenado, coherente y específico. Destina un capítulo a la poesía del siglo XVI refiriéndose sucintamente a varias obras pero dedicando un análisis monográfico a La Araucana. Examina las tres partes y destaca su fidelidad histórica, y la unión en el autor del genio poético y el heroísmo, pero no cualquier heroísmo, sino expresamente un "heroísmo español" (140). El tratamiento generoso de los araucanos lo atribuye a "nobles inspiraciones de carácter español" (143). Destaca la capacidad descriptiva y el talento narrativo del autor en los asuntos bélicos, en las estampas costumbristas y en las arengas araucanas. Para Ticknor, la exactitud geográfica y cronológica de los acontecimientos ya no supone una falta en el plan poético, pero sí se refiere al escaso conocimiento de las normas de la épica que había en el siglo XVI en España: "es preciso confesar que si bien dicha obra revela gran ingenio y mucho sentimiento poético, tiene también graves defectos, por haberse escrito cuando los elementos de la poesía épica estaban muy mal comprendidos en España" (140-141). Aunque se ubica a la obra en el canon de la poesía épica (y de la idiosincrasia hispánica), señala que no se trata de una epopeya en sentido estricto, sino de un poema histórico. La obra de Ticknor tuvo gran repercusión y fue fundamental en términos pedagógicos, como obra de consulta y referencia, tanto en España como en el mundo hispanoparlante.

En el plano historiográfico, Marcelino Menéndez Pelayo introduce por primera vez el doble canon, reconociendo La Araucana como poema español, pero también como poesía chilena. En su Historia de la poesía Hispanoamericana (1893), con una perspectiva de mapeo enciclopédico de cuño positivista, constata una excepcionalidad en la literatura colonial chilena destacando la centralidad literaria de la Guerra de Arauco como tema para poetas, historiadores y arbitristas. En este plano, percibe a La Araucana como un ejemplo notable de la renovación del género histórico y heroico. Califica a Ercilla como un renovador que aporta nuevos temas al arte "nuevas tierras, gentes bárbaras, costumbres exóticas, hazañas y atrocidades increíbles" (Menéndez Pelayo Historia). Señala su riqueza en pormenores expresivos, 
en la creación de caracteres, la descripción de batallas y la comparación con animales. Como todos sus antecesores, va en dos direcciones: alaba la capacidad narrativa en verso y su estilo, señala que "es el mejor de nuestros poemas históricos, y la primera obra de las literaturas modernas en que la historia contemporánea apareció elevada a la dignidad de la epopeya" (219), dice que el "arte de contar ... está llevado en La Araucana a un grado de perfección a que llegan muy pocos libros ni en verso ni en prosa” (220). Incluso apunta que:

No hay literatura en el mundo que tenga tan noble principio como la de Chile, la cual empieza nada menos que con La Araucana, obra de ingenio español, ciertamente, pero tan ligada con el suelo que su autor piso como conquistador, y con las gentes que allí venció, admiró y compadeció a un tiempo, que sería grave omisión dejar de saludar de paso la gran figura de Ercilla (Menéndez y Pelayo Historia 220)

Pero luego, en otros textos de la Antología, se refiere al "desaliño" en algunas estrofas, señala que es de "lectura penosa" (615) pues "Allí rueda solo el carro de Marte, con el mismo son duro y estridente, durante 37 larguísimos cantos" (616).

A fines del siglo XIX, James Fitzmaurice-Kelly publica $A$ history of Spanish Literature (1898), traducida al español en 1901, al francés en 1904, y publicada en varias ediciones en Argentina e Hispanoamérica, lo que avala su extenso uso pedagógico. El hispanista británico ubica La Araucana en el capítulo "Época de Felipe II", en la tradición épica española, pero luego afirma que "ni por su forma, ni por la impresión que produce, es poema épico" (218). Si bien no la incluye en el canon hispanoamericano, señala que es la "primera obra de verdadero valor literario que se compuso en los continentes americanos" (ibid.). Reincide en la idea que en La Araucana el historiador vence al poeta, también en señalar algunos versos y "trozos flojos" (219). No recoge las ideas de Menéndez Pelayo del doble canon, pues luego de la referencia al continente americano retorna el poema al cajón español.

Entre las décadas de 1930 a 1970, que coincidieron con la Guerra Civil Española y la Segunda Guerra Mundial, se publican varias historias de la literatura española, algunas de ellas por profesores que emigran temporal 
o definitivamente a universidades norteamericanas y otros a México e Hispanoamérica. Incluso quienes permanecen en España, por conexiones con académicos exilados, son invitados a Estados Unidos como profesores visitantes en el área de literatura española. Entre estas historias destacan las de Ángel Valbuena Prat (1937), José Manuel Blecua (1944), Ángel del Río (1948), Guillermo Díaz Plaja (1949) y Juan Luis Alberg (1966). Todas ellas mantienen la canonización tradicional de La Araucana como poema épico español del género histórico, sin embargo, se adscribe la obra a categorías como "poesía épica de indias" o de "tema indiano" (Valbuena Prat), o poema épico de "sentimiento americano" (Ángel del Río), o "épica española ultramarina" (Guillermo Díaz Plaja) o poemas de "asunto americano" (Juan Luis Alborg); es decir, se califica al poema como épico renacentista español, pero vinculado temáticamente a América. Tal como en la crítica anterior, se destacan aspectos como el realismo narrativo y la objetividad descriptiva, el relato de las batallas, las arengas, los símiles, y se critican otros como episodios europeos desligados del argumento central, o estrofas con rimas y cadencias algo flojas. Un dato significativo son las numerosas reediciones que tuvieron varias de estas historias, lo que da cuenta de su efecto multiplicador (en cursos del área de Literatura Española a nivel universitario) y el interés pedagógico de las mismas tanto en Estados Unidos como en América Latina, particularmente en el Cono Sur.

Paralelamente a los críticos españoles, se publican algunos europeos como Ludwig Pfandl con su Historia de la literatura nacional española en la edad de Oro (1952), que abarca desde 1550 hasta 1700. El propósito de esta historia es deslindar la producción literaria española frente a conceptos como panhispanismo o iberoamericanismo. Destaca también la importancia de la literatura áurea en la fijación del idioma nacional: el español y ya no el castellano. Recoge la idea de ubicar la obra de Ercilla bajo el rótulo de "poesía épica de temas de indias", apuntando así a la compenetración de lo español y lo americano. A pesar de que Pfandl fue discípulo de Menéndez Pelayo, no recoge — como este- la doble adscripción a España y a América/Chile. 


\section{PLURALISMO Y HETEROGENEIDAD}

En las últimas cuatro décadas se producen cambios importantes en la historiografía literaria española, que coinciden con la muerte de Franco (1975) y el advenimiento de la democracia (1978). Prácticamente todas las historias son obras colectivas, lo que las diferencia con la historiografía literaria tradicional. En un clima de libertad intelectual se publica una Historia social de la literatura española (1981), de Carlos Blanco Aguinaga, Julio Rodríguez Puértolas e Iris Zavala, donde con una perspectiva histórico materialista y antiimperialista se lee la obra de Ercilla como la de un poeta del Imperio Español en que los episodios de San Quintín y de Lepanto no resultan ajenos sino que se perciben como "elementos imprescindibles en una visión nacionalista de la España de los Austria" (302) en función épico-patriótica e imperialista. Se vincula a La Araucana con el Inca Garcilaso de la Vega, "defensores ambos del gigantismo imperial, pero comprensivos admiradores del mundo indígena americano" (Blanco Aguinaga et. al. 303). Francisco Rico dirige y coordina la Historia y crítica de la literatura española (2004), en la que participan varios autores. El capítulo sobre Ercilla y su obra es de Carlos Albarracín-Sarmiento, quien analiza la perspectiva del narrador o hablante lírico (narrador cronista y moralista). A diferencia de la crítica anterior, destaca la labor que se adjudica a su autor desde su arribo a Chile, representándose asimismo como cronista de lo visto y lo vivido, imagen que se pliega al modelo renacentista de las armas y las letras. No hay referencia al carácter de épica viajera, ni se aborda el tema del doble canon. Lo importante es que, sin explicitarlo, el autor alude a la fusión en La Araucana de dos géneros: la crónica y la épica, lo que deja de lado los prejuicios neoclásicos respecto a dos almas supuestamente antagónicas: la del historiador y la del poeta.

Carlos Alvar, José Carlos Mainer y Rosa Navarro, publican Breve historia de la literatura española (1997), obra que asume críticamente el rótulo que lleva por título. Allí, Mainer señala como un problema el estudio cronológico y causal de los hechos artísticos, y advierte que el campo literario debe incluir más que la propia y tradicional literatura vinculada a la alta 
cultura. Discute, por lo tanto, el modelo de la historiografía literaria que viene desde los siglos XVIII y XIX, en que operan referentes patrióticos que buscan conformar una literatura nacional homogénea que sea expresión de un carácter nacional también homogéneo, modelo que ideológicamente está a la sombra del liberalismo, del romanticismo y del positivismo. La Breve historia se propone hablar de la variedad y de la unidad en 800 años de historia literaria. En "Lectores y libros", trata a La Araucana como poema español heroico-histórico, destaca la rotunda musicalidad de algunas octavas, la fuerza de sus comparaciones y la intensidad del estilo, sin hacerse cargo, empero, de la ambigüedad ideológica del poema.

En la Historia de la literatura española (2013) dirigida por Juan Carlos Mainer y con participación de varios autores, Mainer se refiere a cierto descrédito de las historias literarias nacionales, a las que concibe como un recuento de autores y formas literarias. Historias que gozaron de fama durante el siglo XIX y primera mitad del siglo XX y que fueron concebidas bajo el modelo romántico-positivista. Señala que en la literatura actual hay géneros nuevos, y un campo literario en que la separación entre lo culto y lo popular se ha tornada difusa. También, que España ya es plurinacional en términos culturales y de lengua. Recuerda, además, la idea de que el recorte nacionalista limitó la realidad cultural y omitió o desconoció las tensiones y heterogeneidad del campo literario y cultural en el siglo XVI. Ahora, lo que se señala del poema no se condice con la propuesta crítica que hace de la historiografía nacionalista, pues si bien se hace cargo de la diversidad sociocultural de la península como un factor que la historia literaria debería considerar, no ocurre lo mismo con respecto a la semanticidad ambigua y contestataria presente en La Araucana, o en algunas crónicas ultramarinas como la de Alvar Núñez Cabeza de Vaca. 


\section{ESTUDIOS E INVESTIGACIONES}

En las últimas décadas se han realizado algunos estudios e investigaciones en España y Francia sobre La Araucana, que no podrán ser desconocidas por la futura historiografía literaria. Se trata, por una parte, de la aceptación explícita del doble canon, y por otra, de la superación del contraste entre historia y poesía. La doctora en Filología Hispánica Eva Valero, en varios trabajos, ha puesto en evidencia que la crítica a la codicia de conquistadores y viajeros fue un motivo recurrente en la literatura de viajes a las Indias en el siglo XVI. Percibe en La Araucana, frente al modelo de conquista y explotación imperialista, un ideal de convivencia igualitaria y pacífica entre pueblos diferentes ${ }^{3}$. En 2016, publica Ercilla y La Araucana en dos tiempos. Del siglo de oro a la posteridad, investigación en que analiza el poema en su adscripción y recepción tanto española como chilena, nombrándolo poema español del Siglo de Oro, a la vez que poema inaugural de la literatura chilena. Examina la recepción y apropiación en Chile, entre otros por Andrés Bello, Gabriela Mistral, Pablo Neruda y Raúl Zurita. Da cuenta de personajes araucanos que han tenido repercusión y han sido recreados literariamente por una serie de autores chilenos desde el siglo XIX hasta el presente. Engarza el proceso literario de la obra (en tanto piedra angular de la literatura chilena) con nuevos sentidos vinculados a la historia del país. Los "dos tiempos" a que se refiere el título apuntan a la doble canonización y a la presencia en la obra de Ercilla de dos tiempos históricos diferentes: el que viven los conquistadores españoles y el que viven los habitantes de Arauco. En la academia, a su vez, se imponen denominaciones o conceptos puente como "épica indiana", "épica americana" o "épica colonial". Será difícil, luego del libro de Valero y de los estudios contemporáneos, ignorar o desconocer el doble registro y la doble militancia de La Araucana.

3 En "Por el camino del mar, el viaje hacia el ideal de Alonso de Ercilla" (2008), Eva Valero Juan coincide en este aspecto con Discursos narrativos de la Conquista: mitificación y emergencia (1988), de Beatriz Pastor, y con los textos de Gilberto Triviños "No hay bien que dejemos en el olvido/el nombre de este bárbaro obstinado" y "Lecturas de la Araucana" en Épica y Colonia: ensayos sobre el género épico en Iberoamérica (siglos XVI al XVII) (2008). 
Lara Vilá señala, respecto a la tensión entre historia y poesía, tópico predilecto de la crítica de cuño neoclásico, que el enfoque estético normativo llevó a menospreciar el abordaje de hechos recientes y el afán histórico y testimonial. Advierte que, ya en el siglo XVI, La Farsalia de Lucano (en la que se poetizan temas históricos del presente) operó como modelo, contrariando así la preceptiva aristotélica. Varios poemas épicos históricos españoles de la época de Ercilla tratan hechos contemporáneos y obedecen a una voluntad compositiva que busca fusionar la historia con la poesía (Vilá).

La estudiosa francesa Aude Plagnard, en Une épopée ibérique: Alonso de Ercilla et Jerónimo Corte-Real (2019), se refiere al enfoque estético preceptivo que consideraba una debilidad literaria la fidelidad histórica. Demuestra que, a contrario sensu, en la época se daba un interés por los relatos históricos, que eran percibidos como servicio al soberano y a la grandeza de la monarquía. Frente a quienes han leído la factura o carácter histórico de estos poemas como un déficit de poeticidad, demuestra que la conjunción entre dos géneros (la crónica y la poesía, lo histórico y lo estético) era un ideal de un nuevo ethos épico que no ha sido plenamente reconocido ni por la historiografía ni por la crítica. La oposición entre un discurso poético y la observación de hechos y fenómenos particulares (lo visto y lo vivido) no era en los tiempos de Felipe II una oposición operante en el plano de la creación. La contundencia de datos y documentos con que la estudiosa francesa demuestra su hipótesis viene a cuestionar dichos enfoques tradicionales binarios. Se trata, sin duda, de investigaciones que permiten relativizar algunos puntos de vista presentes en la historiografía literaria tradicional, y que tomadas en conjunto abren las puertas para una épica viajera tan vinculada a España como a Chile, a Europa como al mundo americano, vale decir, a lo humano sin fronteras. La cultura, a fin de cuentas, ha sido siempre, en una de sus vertientes, la apropiación pacífica de bienes ajenos. 


\section{A MODO DE CONCLUSIÓN}

El contexto de producción y recepción de La Araucana en el siglo XVI, con indicadores de edición y circulación sorprendentes para la época, sitúa a la obra como un poema épico vinculado al Imperio de Felipe II y canonizado como una de las mejores piezas del género épico español. Juicio que expresaron también directa o indirectamente autores significativos de la época, como Lope de Vega y Cervantes. Contribuyen también a esta fama reescrituras que a fines del siglo XVI y comienzos del XVII popularizan a personajes araucanos, o los deconstruyen desde un trasfondo contrarreformista ajeno al humanismo erasmista de La Araucana. Otro autor continúa la obra con una Cuarta y Quinta Parte, transgrediendo el final abierto sobre la Guerra de Arauco. Son reescrituras que omiten las zonas de indeterminación semántica para reinscribir elementos, personajes o motivos en códigos afines al anclaje español, en un momento histórico finisecular de aires imperiales y contrarreformistas. Una perspectiva muy distinta de lectura se constata en el mundo anglosajón, sobre todo durante el siglo XVIII y a comienzos del XIX, pues se enmarca en disputas imperiales y en un romanticismo que se entusiasma con la visión positiva que esgrime Ercilla del espíritu libertario e indómito de los líderes araucanos. Ello nos indica que La Araucana es una obra abierta y compleja, cuyo sentido va mutando de acuerdo con distintos contextos históricos de recepción.

En el siglo XVIII, en géneros híbridos que no son propiamente historias literarias en un sentido tradicional, sino más bien selecciones y antologías, se destacan aspectos de la obra y se critican otros desde miradas próximas a las poéticas neoclásicas. Siempre, sin embargo, manteniendo a la obra dentro del canon español. Un punto de inflexión lo constituye la lectura que hace José Luis Munárriz a comienzos del siglo XIX, autor que destaca sus logros estilísticos y estéticos, pero que al mismo tiempo la crítica en términos ideológicos nacionalistas, señalándola como una obra que es desleal a España, en la medida que ensalza a los araucanos y denosta al bando español y a la Conquista. Esta crítica tendrá algunos continuadores y abrirá, sin explicitarlo, 
un espacio para una posible migración canónica. Las historias literarias propiamente tales, regidas por el modelo positivista nacional, mantienen a la obra de Ercilla en el canon hispánico destacándola como una de las más logradas piezas épicas de la España renacentista. A fines del siglo XIX, sin embargo, Marcelino Menéndez Pelayo la reconoce como poema español, pero también como un poema chileno e hispanoamericano, con lo que se abre y explicita la posibilidad de un doble canon. Asunto que, con la transformación de las historias literarias, sumado a nuevas investigaciones, abrirá desde la propia España la posibilidad de una doble pertenencia de La Araucana en términos de identidad nacional y literaria.

\section{REFERENCIAS}

Alvar, Carlos, et al. Breve historia de la literatura española. Madrid: Alianza Editorial, 1997.

Amor, José. "Ercilla y sus lectores". Actas del VI congreso internacional de la Asociación de Lingüistica y Filología de la América Latina: Phoenix, Arizona (1981): 935-950.

Blanco Aguinaga, Carlos, Julio Rodríguez Puértolas e Iris M. Zavala. Historia social de la literatura española (en lengua castellana). Madrid: Castalia, 1981.

Chevalier, Maxime. Lectura y lectores en la España del siglo XVI y XVII. Madrid: Turner, 1976.

Cole, Rebeca. “"Thy World, Columbus, Shall Be Free': British Romantic Deviance and Spanish American Revolution". European Romantic Review 17.2 (2006): 151-159.

De Claramonte, Andrés. Autosacramental La Araucana. Estudio, edición y notas de Rodrigo Faúndez Carreño. Santiago de Chile: Editorial Universitaria, 2018.

De la Revilla, Manuel. Principios generales de la literatura española. Vol. I. Imprenta Pascual Conesa, 1877. 
De León Pinelo, Antonio. Epitome de la Biblioteca oriental $i$ occidental, naútica i geográfica. Madrid: 1629.

De Vega, Lope. Laurel de Apolo. Londres: Richards, St.-Martin's Lane, Charing-Cross, 1824.

Fitzmaurice-Kelly, James. Historia de la literatura española. Buenos Aires: Ediciones Anaconda, 1942.

Fuchs, Barbara. "Traveling Epic: Translating Ercilla's La Araucana in the Old World". Journal of Medieval and Early Modern Studies 36 (2006): 379-395.

Gil de Zárate, Antonio. Manual de literatura española. Madrid: Imprenta y Librería de Ignacio Boix, 1844.

Heinowitz, Rebecca Cole. “"Thy World, Columbus, Shall Be Free': British Romantic Deviance and Spanish American Revolutio". European Romantic Review 17.2 (2006): 151-159.

Mainer, José Carlos, Jorge García López et al. Historia de la literatura española. Tomo II. Barcelona: Crítica, 2013.

Martínez Chacón, Elena. “Arauco Domado, Lope de Vega y Ercilla. Motivación de venganza y panegírico". Revista Chilena de Literatura (1980): 229256.

Martínez de la Rosa, Francisco. "Anotaciones a la Poética. Apéndice sobre la poesía épica española”. Obras Literarias. París: Imprenta Julio Didot, 1827-1830.

Martínez, Miguel. "Writing on the edge: the poet, the printer, and the colonial frontier in Ercilla's La Araucana (1569-1590)". Colonial Latin American Review 26.2 (2017): 132-153.

Massmann, Stefanie. "Poetas y cronistas: consideraciones sobre la reescritura de 'La araucana' en el discurso historiográfico del siglo XVI chileno". Chasqui 41.2 (2012): 33-50.

Medina, José Toribio. La Araucana de D. Alonso de Ercilla y Zúñiga: edición del centenario. Santiago de Chile: Imprenta Elzeviriana 1917. 
Medina, José Toribio. Los romances basados en La Araucana: con su texto y anotaciones, y un estudio de los que se conocen sobre la América del Sur anteriores a la publicación de la primera parte de aquel poema. Santiago de Chile: Imprenta Elzeviriana, 1918.

Menéndez y Pelayo, Marcelino. Antología General de Menéndez Pelayo: Recopilación orgánica de su doctrina. Tomo II. Comp. J. M. Sánchez de Murain. Madrid: Editorial Católica, 1956.

Menéndez y Pelayo, Marcelino. Historia de la poesía hispanoamericana. Vol. II. Madrid: Editorial Nacional, 1948.

Milá y Fontanals, Manuel. Compendio del arte poética. Barcelona: Imprenta de D.J.M. de Grau, 1844.

Munárriz, José Luis y Hugh Blair. “Apéndice sobre la poesía épica española”. Compendio de las lecciones sobre la retórica y bellas artes de Hugo Blair. Madrid: Imprenta del Censor, 1819.

Núñez Sepúlveda, Ariel. "Tucapel, de guerrero a gracioso: variaciones de un personaje araucano en el teatro del Siglo de Oro". Hipogrifo: Revista de Literatura y Cultura del Siglo de Oro 6.1 (2018): 129-146.

Pérez Pastor, Cristóbal. Bibliografía madrileña. Madrid: Tipografía de los Huérfanos, 1891.

Pérez, Joseph. Humanismo en el Renacimiento español. Madrid: Gadir, 2013. Pfandl, Ludwig. Historia de la literatura nacional española en la Edad de Oro. Trad. por Rubio Balaguer. Barcelona: Gili, 1952.

Picón, Daniela. "Recepción de La Araucana en el radicalismo inglés: William Hayley y Robert Southey". Inédito.

Pierce, Franck "The fame of the Araucana", Bulletin of Hispanic Studies 59.3 (1982): 230-236.

Pierce, Frank. "Ercilla and England". Hispanic Studies in Honour of I.González Llubera. Oxford: The Dolphin Book, 1959.

Pierce, Frank. "Ercilla's Irish Translator, Henry Boyd”. Studia Philologica: Homenaje ffrecido a Dámaso Alonso por sus amigos y discípulos con ocasión de su $60^{\circ}$ aniversario. Vol II. Madrid: Gredos, 1961.

Pierce, Frank. La poesía épica en el siglo de oro. Madrid: Gredos, 1961. 
Plagnard, Aude. Une épopée ibérique. Alonso de Ercilla et Jerome Corte-Real (1569-1589). Madrid: Casa de Velázquez, 2019.

Quintana, Manuel José. Poesías selectas castellanas, desde el tiempo de Juan de Mena hasta nuestros días. Madrid: Gomez Fuentenebro, 1807.

Rodríguez Patón, Bartolomé. Elocuencia española. 1621.

Simonde de Sismondi, Jean-Charles-Léonard. De la litterature du midi de l'Europe. Treuttel et Wurtz, 1813.

Suárez de Figueroa, Cristóbal. Los hechos de Don García. Madrid: Imprenta Real, 1613.

Subercaseaux, Bernardo. "La Araucana: recepción y virtualidad semántica". Hispamérica: Revista de literatura 140 (2018): 13-24.

Ticknor, George. Historia de la literatura española. Tomo III. Madrid: Imprenta y Estereotipia de M. Rivadeneyra, 1854.

Valero Juan, Eva. "Por el camino del mar, el viaje hacia el ideal de Alonso de Ercilla". Revista Atenea 498 (2008): 11-31. . Ercilla y La Araucana en dos tiempos. Del siglo de oro a la posteridad. Sevilla: Renacimiento, 2016.

Vilá, Lara "La épica española del Renacimiento (1540-1605)", Boletín de la Real Academia Española, Tomo 83, Cuaderno 287 (2003): 137-150.

Voltaire. Ensayo sobre la poesía épica y el gusto de los pueblos. Madrid: Editorial Mundo Latino, 1930. 